\title{
Efeito dos níveis de concentrado sobre o desempenho de ovinos Morada Nova em confinamento ${ }^{1}$
}

\section{Geovergue Rodrigues de Medeiros ${ }^{2}$, Francisco Fernando Ramos de Carvalho ${ }^{3}$, Marcelo de Andrade Ferreira ${ }^{3}$, Ângela Maria Vieira Batista ${ }^{3}, K_{\text {Kaliandra Souza Alves }}^{4}$, Rinaldo José de Souto Maior Júnior ${ }^{5}$, Sidnei Celestino de Almeida ${ }^{6}$}

${ }^{1}$ Parte da tese de Doutorado do primeiro autor, apresentada ao Programa de Doutorado Integrado em Zootecnia - UFRPE/UFPB/UFC - Projeto financiado pela FACEPE/CNPq.

2 Escola Agrotécnica Federal de Codó - MA

${ }^{3}$ Departamento de Zootecnia - UFRPE - Recife - PE.

4 Universidade Federal Rural da Amazônia - Parauapebas - PA.

${ }^{5}$ Mestrando em Zootecnia - UFRPE - Recife - PE.

6 Zootecnista, BS

RESUMO - Avaliaram-se o desempenho e a digestibilidade dos nutrientes em 32 ovinos Morada Nova, castrados, em confinamento alimentados com dietas contendo $20,40,60$ e $80 \%$ de concentrado. Os animais tinham $8,11 \pm 1,15$ meses de idade, peso inicial de 19,67 $\pm 2,97 \mathrm{~kg}$ e peso ao abate de $30,0 \mathrm{~kg}$. Utilizou-se delineamento experimental em blocos casualizados, com quatro tratamentos e oito repetições. Houve efeito linear decrescente dos níveis de concentrado sobre o número de dias em confinamento, que variou de 123,37 a 52,50 para as dietas com 20 e 80\% de concentrado. O consumo diário de MS aumentou linearmente com a redução da proporção volumoso:concentrado, que variou de 0,925 a 1,124 kg. O ganho de peso, a conversão e a eficiência alimentar melhoraram com aumento do nível de concentrado na dieta. Os consumos de MO, PB, EE, NDT, EM, carboidratos totais (CT) e carboidratos não-fibrosos (CNF) elevaram, enquanto os de FDN e FDA decresceram com a inclusão do concentrado. Os coeficientes de digestibilidade de MS, MO e dos CT foram crescentes, enquanto a digestibilidade do EE e dos CNF sofreram efeito quadrático e as digestibilidades de PB, FDN e FDA não foram influenciadas pelo aumento de concentrado na dieta. Níveis de concentrado acima de $60 \%$ elevaram os ganhos de peso e anteciparam a idade ao abate dos ovinos Morada Nova. Dietas com níveis superiores a $40 \%$ de concentrado melhoraram os índices de digestibilidade aparente dos nutrientes. A raça Morada Nova tem potencial para produção de carne em confinamento.

Palavras-chave: consumo, energia, ganho de peso, engorda

\section{Effect of concentrate level on performance of feedlot Morada Nova sheep}

ABSTRACT - The objective of this trial was to evaluate performance and nutrient intake and digestibility in feedlot Morada Nova hair sheep fed increasing levels of dietary concentrate. Thirty-two castratated Morada Nova sheep averaging $8.11 \pm 1.15$ months of age and $19.67 \pm 2.97 \mathrm{~kg}$ of body weight $(\mathrm{BW})$ at the beginning of the study were used in this trial. Animals were slaughtered with $30.0 \mathrm{~kg}$ of BW and fed diets with the following concentrate levels: $20,40,60$ or $80 \%$. A completely randomized block design with eight replicates per treatment was used. There was a significant linear reduction in feedlot days from 123.37 to 52.50 when the concentrate levels increased from 20 to $80 \%$ in the diet. Conversely, dry matter intake increasead linearly from 0.925 to $1.124 \mathrm{~kg} / \mathrm{day}$ by reducing the forage:concentrate ratio of the diet. The daily weight gain and feed conversion and efficiency improved with increasing the levels concentrate in the diet. Intakes of organic matter, crude protein, ether extract, total digestible nutrients, metabolizable energy, total carbohydrates, and nonfiber carbohydrates all increasead with concentrate levels in the diet, while the opposite was observed for intakes of neutral detergent fiber and acid detergent fiber. Total tract apparent digestibility of dry matter, organic matter, and total carbohydrates increased when the concentrate levels was increased in the diet. Significant quadratic effects were observed for the the digestibility of ether extract and nonfiber carbohydrates while that of crude protein, neutral detergent fiber and acid detergent fibers was not affected by the dietary levels of concentrate. Dietary concentrate levels greater than $60 \%$ improved performance of feedlot Morada Nova sheep by increasing daily weight gain and decreasing slaughter feedlot time. Diets with concentrate levels higher than $40 \%$ increasead digestibility coefficients of nutrients.

Key Words: energy, finishing, intake, weight gain 


\section{Introdução}

O confinamento de ovinos tem sido estimulado para atender às exigências do mercado consumidor por carcaças de melhor qualidade, bem como manter a regularidade da oferta de carne durante todo o ano, contribuindo para elevar as taxas de desfrute dos rebanhos.

A prática de confinamento também reduz as perdas de animais jovens por deficiências nutricionais e infestações parasitárias, proporciona retorno mais rápido do capital investido e diminui a idade ao abate e a pressão de pastejo na caatinga, disponibilizando forragens para outras categorias animais (Siqueira, 2000; Vasconcelos, 2000; Barros et al., 2003). Deve-se atentar, no entanto, a fatores como o plano nutricional, a idade, o sexo, o peso de abate e o genótipo, diretamente relacionados ao desempenho e a aspectos qualiquantitativos das carcaças dos ovinos produzidos (Field et al., 1990; Snowder et al., 1994; Quintero et al., 2002).

Notter et al. (1991) e Haddad \& Husein (2004) reportaram que, para obtenção de ganhos que compensem economicamente a prática de confinamento, a dieta deve ser de alta energia e conter adequados níveis de proteína (Manso et al., 1998; Titi et al., 2000) com vistas a reduzir o tempo de permanência dos animais na fase de terminação, elevar as taxas de ganho de peso, a eficiência alimentar e, conseqüentemente, diminuir os custos de produção. No entanto, diante da necessidade de aumentar a densidade energética das dietas, verifica-se a maximização do uso de concentrados, que pode acarretar maior possibilidade de distúrbios metabólicos (Alves et al., 2003a), sobretudo alterações no pH ruminal (Phy \& Provenza, 1998; Santra et al., 2003). A utilização de volumosos também é importante nas dietas de animais confinados, pois a fibra é essencial para estimular a mastigação e ruminação (Coelho da Silva \& Leão, 1979; Van Soest, 1994). Dietas que não estimulam adequadamente a mastigação reduzem a produção de saliva, resultando em diminuição do $\mathrm{pH}$ ruminal e comprometendo a digestibilidade da fibra (Grant \& Mertens, 1992).

Zeola (2002) verificou que umadieta com $60 \%$ de concentrado proporcionou maior ganho de peso, em torno de 172 g/dia, com conversão alimentar de 4,72 em ovinos Morada Nova em confinamento.

Com ovinos Pelibuey, no México, Fimbres et al. (2002b) verificaram que o aumento no nível de feno na dieta $(0,10$, 20 e $30 \%$ ) esteve associado aos menores ganhos de peso $(0,250 ; 0,207 ; 0,203$ e $0,174 \mathrm{~kg} / \mathrm{dia})$, respectivamente.

Alves et al. (2003a), utilizando dietas com 2,42; 2,66 e 2,83 Mcal de EM/kg MS, constataram que não houve efeito significativo do nível de EM na dieta sobre o consumo de
MS, o ganho de peso diário e a conversão alimentar de ovinos Santa Inês em confinamento, no entanto, recomendaram a utilização de 2,83 Mcal de EM/kg de MS por ter proporcionado menor período de confinamento (76,67 dias) e, conseqüentemente, maior margem bruta de lucro. Resultados similares também foram encontrados por Barros et al. (2003), que, avaliando o desempenho de cordeiros Santa Inês $\times$ SRD (sem raça definida) e Somalis $\times$ SRD alimentados com dietas com 15,30, 45 e $60 \%$ de concentrado, não observaram efeito do nível de concentrado da dieta sobre o ganho de peso dos animais. Os ovinos Somalis $\times$ SRD apresentaram ganhos de 171,6 g/dia, enquanto os Santa Inês $\times$ SRD alcançaram $134,7 \mathrm{~g} /$ dia.

Este trabalho foi realizado com o objetivo de avaliar o efeito de níveis crescentes dos níveis de concentrado sobre o desempenho e a digestibilidade dos nutrientes em ovinos Morada Nova em confinamento.

\section{Material e Métodos}

O experimento foi conduzido no galpão de confinamento do Setor de Caprino-ovinocultura do Departamento de Zootecnia da Universidade Federal Rural de Pernambuco, em Recife-PE, situada na microrregião fisiográfica do Litoral Mata, pertencente à Região Metropolitana do Recife.

Foram utilizados 32 ovinos Morada Nova, variedade vermelha, machos castrados, com 8,11 $\pm 1,15$ meses de idade, peso inicial de 19,67 $\pm 2,97 \mathrm{~kg}$ e peso ao abate (PVA) de $30,0 \mathrm{~kg}$, confinados em baias individuais de $1,0 \times 2,8 \mathrm{~m}$, com $0,80 \mathrm{~m}$ do piso cimentado (local do cocho) e $2,0 \mathrm{~m}$ em chão batido, providas de comedouros e bebedouros, onde receberam as dietas experimentais. Os animais foram pesados, identificados, tratados contra ecto e endoparasitas e vacinados contra clostridioses. As pesagens ocorreram a cada sete dias, do início do experimento até alcançarem o peso de abate. As análises de composição bromatológica dos alimentos, das sobras e das fezes dos animais foram realizadas no Laboratório de Nutrição Animal do Departamento de Zootecnia da Universidade Federal Rural de Pernambuco.

As determinações de MS, cinzas, PB, EE e lignina em detergente ácido (LDA) foram feitas segundo metodologia descrita por Silva \& Queiroz (2002). Para determinação das frações da parede celular, FDN e FDA, utilizou-se a metodologia descrita por Van Soest et al. (1991) e recomendada pelo fabricante do aparelho ANKOM Technology ${ }^{\circledR}$, com modificação em relação aos sacos - utilizaram-se sacos de polipropileno (tecido-não-tecido, gramatura $100 \mathrm{~g} / \mathrm{m}^{2}$ ). Os teores de compostos nitrogenados insolúveis em detergente neutro (NIDN) e em detergente ácido (NIDA) foram 
Tabela 1 - Composição bromatológica dos ingredientes das dietas experimentais

Table 1 - Chemical composition of ingredients used in the experimental diets

\begin{tabular}{|c|c|c|c|c|c|c|c|c|c|c|}
\hline $\begin{array}{l}\text { Ingrediente } \\
\text { Ingredient }\end{array}$ & $\begin{array}{l}\text { MS } \\
D M\end{array}$ & $\begin{array}{l}\text { MO } \\
O M\end{array}$ & $\begin{array}{c}\text { Cinzas } \\
\text { Ash }\end{array}$ & $\begin{array}{l}\mathrm{PB} \\
C P\end{array}$ & $\begin{array}{l}\mathrm{EE} \\
E E\end{array}$ & $\begin{array}{l}\text { FDN } \\
N D F\end{array}$ & $\begin{array}{r}\mathrm{FDN}_{\mathrm{CP}} \\
N D F_{C P}\end{array}$ & $\begin{array}{l}\text { FDA } \\
A D F\end{array}$ & $\begin{array}{l}\mathrm{CNF} \\
N F C\end{array}$ & $\begin{array}{l}\mathrm{NDT} \\
T D N\end{array}$ \\
\hline Feno de capim-tifton (Tif & 89,07 & 91,86 & 8,14 & 8,45 & 1,72 & 79,02 & 75,77 & 41,08 & 5,91 & $49,78^{2}$ \\
\hline Milho moído(Ground corn) & 87,76 & 98,31 & 1,69 & 10,55 & 4,04 & 21,12 & 12,67 & 4,97 & 62,92 & $86,02^{2}$ \\
\hline Farelo de soja (Soybean meal) & 88,72 & 92,24 & 7,76 & 52,21 & 1,62 & 17,35 & 16,90 & 10,96 & 21,41 & $79,18^{2}$ \\
\hline Óleo vegetal (Vegetable oil) & 100 & - & - & - & $99,9^{1}$ & - & - & - & - & $184,0^{1}$ \\
\hline
\end{tabular}

${ }^{1}$ Valores da tabela de composição de ingredientes do NRC (2001).

2 Estimado pela equação de Weiss (1999).

1 Values from the ingredient composition table of NRC (2001).

${ }^{2}$ Estimated according to Weiss (1999).

estimados pelo procedimento de micro Kjeldahl nos resíduos obtidos da FDN e FDA corrigidas para nitrogênio insolúvel em detergente neutro e ácido, respectivamente (Tabela 1).

As dietas experimentais continham 15,91 a 18,35\% de PB e foram formuladas com feno moído de capim-tifton 85 (Cynodon dactylon) e diferentes níveis de concentrado (20, 40, 60 e $80 \%$ ), composto de milho e farelo de soja e óleo vegetal. Além desses ingredientes, utilizaram-se mistura mineral, calcário calcítico e bicarbonato de sódio (Tabela 2). A dieta de maior nível de concentrado foi formulada de acordo com o NRC (1985), para atender às exigências nutricionais de animais com $20 \mathrm{~kg}$ de PV e ganho diário de $250 \mathrm{~g} / \mathrm{animal} / \mathrm{dia}$.

O fornecimento das dietas experimentais foi feito uma vez ao dia, na forma de dieta completa, com água permanentemente à disposição dos animais. $\mathrm{O}$ alimento ofertado e as sobras foram pesados diariamente para cálculo do consumo voluntário e reajuste da quantidade oferecida, estabelecendo-se $10 \%$ de sobras.

Decorridos 28 dias do período experimental, procedeu-se ao ensaio de digestibilidade durante sete dias, período em que foram feitas coletas de amostras de alimentos (feno, milho e farelo de soja), sobras e fezes. As amostras foram pesadas, identificadas e armazenadas a $-15^{\circ} \mathrm{C}$ para análises posteriores. No final desse ensaio, as sobras foram homogeneizadas e constituíram uma amostra composta por animal.

As amostras de fezes foram retiradas diretamente da ampola retal dos ovinos, duas vezes ao dia (às 7h30 e às 16h). Ao final do período de coleta, foram homogeneizadas (constituindo uma amostra composta por animal) e présecas em estufa com circulação forçada a $65^{\circ} \mathrm{C}$ por 72 horas. Todas as amostras de alimentos, sobras e fezes foram trituradas em moinho de faca tipo Willey, com peneira de crivo de 1,0 mm, para posteriores análises laboratoriais.

A estimativa da produção de MS fecal (PMSF) foi feita utilizando-se a fibra em detergente ácido indigestível
(FDAi) como indicador interno. Para determinação das concentrações de FDAi nos alimentos, nas sobras e nas fezes, foram incubados $1,0 \mathrm{~g}$ de cada ingrediente do concentrado e $0,5 \mathrm{~g}$ do feno, das sobras e das fezes no rúmen de um búfalo adulto, por um período de 144 horas, em sacos tipo ANKOM ${ }^{\circledR}$ Filter bags F57, segundo metodologia descrita por Berchielli et al. (2000), exceto quanto à incubação, que foi in situ. O material remanescente da incubação foi submetido à extração com detergente ácido, cujo resíduo foi considerado FDAi.

Para estimativa dos carboidratos totais (CT), utilizou-se a equação proposta por Sniffen et al. (1992): CT = $100-$ $(\% \mathrm{~PB}+\% \mathrm{EE}+\%$ Cinzas $)$ e, para estimativa dos carboidratos não-fibrosos (CNF), adotou-se a equação preconizada por Hall et al. (1999): $\mathrm{CNF}=\% \mathrm{CT}-\% \mathrm{FND}_{\mathrm{PB}}$, sendo a FDN corrigida para proteína. O cálculo dos nutrientes digestíveis totais (NDT) foi feito segundo equação proposta por Weiss (1999): $\mathrm{NDT}=(\mathrm{PBd}+\mathrm{CNFd}+\mathrm{FDNcpd}+(\mathrm{EEd} * 2,25))-7$, em que PBD; CNFd; FDNcpd; e EEd significam, respectivamente, consumos de PB, CNF, FDN e EE digestíveis, observando-se que a FDN foi corrigida para proteína.

Para o cálculo da EM (Mcal de EM/kg de MS), inicialmente calculou-se a energia digestível (ED) como o produto entre o teor de NDT e o fator 4,409/100 considerando a concentração de EM de $82 \%$ da ED.

O delineamento experimental utilizado foi o de blocos casualizados, com quatro tratamentos e oito repetições, em que os blocos foram formados pelos animais, de acordo com o peso inicial.

Além da análise de variância, procedeu-se à análise de regressão considerando os níveis de concentrado na dieta. Os critérios utilizados na escolha das equações foram o comportamento biológico, o coeficiente de determinação $\left(\mathrm{r}^{2}\right)$ e a significância para os parâmetros de regressão, obtida pelo teste t a 1 e $5 \%$ de probabilidade. As análises estatísticas foram realizadas com auxílio do programa computacional SAEG (2001). 
Tabela 2 - Composições percentual e bromatológica das dietas experimentais, com base na MS

Table 2 - Ingredient and chemical compositions (\%) of the experimental diets, \% of DM

\begin{tabular}{|c|c|c|c|c|}
\hline \multirow[t]{2}{*}{$\begin{array}{l}\text { Ingrediente } \\
\text { Ingredient }\end{array}$} & \multicolumn{4}{|c|}{$\begin{array}{c}\text { Nível de concentrado, } \% \\
\text { Concentrate level }\end{array}$} \\
\hline & 20 & 40 & 60 & 80 \\
\hline Feno de capim-tifton (Tifton hay) & 78,90 & 60,00 & 40,0 & 20,0 \\
\hline Grão de milho moído (Ground corn) & 0,00 & 18,50 & 36,0 & 54,0 \\
\hline Farelo de soja(Soybean meal) & 17,70 & 18,20 & 20,0 & 21,0 \\
\hline Óleo vegetal (Vegetable oil) & 2,50 & 2,50 & 2,50 & 2,50 \\
\hline Bicarbonato de sódio (Sodium bicarbonate) & 0,00 & 0,00 & 0,00 & 0,50 \\
\hline Cloreto de sódio & 0,20 & 0,10 & 0,00 & 0,00 \\
\hline Calcário calcítico (Limestone) & 0,20 & 0,50 & 0,50 & 0,80 \\
\hline Mistura mineral $^{1}$ (Mineral mix) $^{2}$ & 0,50 & 0,20 & 1,00 & 1,20 \\
\hline \multicolumn{5}{|l|}{ Composição (Composition) } \\
\hline $\mathrm{MS}(D M), \%$ & 89,38 & 89,12 & 88,96 & 88,84 \\
\hline $\mathrm{PB}(C P), \%$ & 15,91 & 16,50 & 17,62 & 18,35 \\
\hline $\mathrm{EE}(E E), \%$ & 4,14 & 4,57 & 4,96 & 5,36 \\
\hline $\mathrm{FDN}(N D F), \%$ & 65,41 & 54,47 & 42,68 & 30,85 \\
\hline $\mathrm{FDN}_{\mathrm{PB}}\left(N D F_{C P}\right), \%$ & 62,77 & 50,88 & 38,25 & 25,54 \\
\hline $\operatorname{FDA}(A D F), \%$ & 34,53 & 27,56 & 20,41 & 13,20 \\
\hline $\mathrm{CT}(T C), \%$ & 71,25 & 71,49 & 70,49 & 69,60 \\
\hline $\mathrm{CNF}(N F C), \%$ & 8,45 & 19,08 & 29,30 & 39,65 \\
\hline Cinzas $(A s h), \%$ & 8,69 & 7,41 & 6,91 & 6,67 \\
\hline $\operatorname{NDT}(T D N), \%$ & 57,89 & 64,79 & 71,31 & 77,63 \\
\hline EM, Mcal/kg de MS (ME, Mcal/kg DM) & 2,10 & 2,34 & 2,56 & 2,81 \\
\hline
\end{tabular}

${ }^{1}$ Níveis de garantia, nutrientes/kg (Garanty levels, nutrients/kg): Ca - $130 \mathrm{~g} ; \mathrm{P}-70 \mathrm{~g} ; \mathrm{Mg}-1.320 \mathrm{mg} ; \mathrm{Fe}-2.200 \mathrm{mg} ; \mathrm{Co}-140 \mathrm{mg} ; \mathrm{Mn}-3.690 \mathrm{mg} ; \mathrm{Zn}-$ $4.700 \mathrm{mg} ; \mathrm{I}-61 \mathrm{mg} ; \mathrm{Se}-45 \mathrm{mg} ; \mathrm{S}-12 \mathrm{~g} ; \mathrm{Na}-170 \mathrm{~g} ; \mathrm{Cl}-276 \mathrm{~g} ; \mathrm{F}$ (máximo) - $700 \mathrm{mg}$; solubilidade mínima de $\mathrm{P}_{2} \mathrm{O}_{5}$ em ácido cítrico a $2 \%=90 \%$ (minimum solubility of $\mathrm{P}_{2} \mathrm{O}_{5}$ in acid citric $2 \%=90 \%$ ).

\section{Resultados e Discussão}

Verificou-se que não houve efeito significativo (P>0,05) do nível de concentrado sobre o peso ao abate, bem como para o ganho de peso total durante o confinamento (Tabela 3).

Todavia, o tempo de permanência dos animais no confinamento $(123,37 ; 86,62 ; 75,25$ e 52,50 dias $)$ decresceu linearmente $(\mathrm{P}<0,05)$ conforme aumentou a quantidade de concentrado na dieta, antecipando a idade ao abate em 70,87 dias no maior nível de concentrado. Apesar de o ganho de peso total durante o confinamento ter sido semelhante entre os níveis de concentrado $( \pm 11,0 \mathrm{~kg})$, ressalta-se que menores períodos de confinamento reduzem a idade ao abate e favorecem as carcaças em termos qualiquantitativos, além de representar menores custos de produção e proporcionar maior rotatividade de animais no confinamento/ano, amortizando mais rapidamente as despesas com instalações e alimentação. Esses resultados corroboram os descritos por Susin (2001), que concluiu que a dieta de custo mínimo em confinamentos é aquela com alto nível de concentrado. Haddad \& Hussein (2004) verificaram que ovinos Awassi alimentados com dietas contendo 40 e $85 \%$ de concentrado ganharam 11,3 e 16,5 kg, respectivamente, aos 63 dias de confinamento.
Alves et al. (2003a) observaram que ovinos Santa Inês alimentados com dietas com 2,42;2,66 e 2,83 Mcal EM/kg de MS atingiram, respectivamente, o peso de abate $(31,0 \mathrm{~kg})$ aos 97,83; 96,50 e 76,67 dias de confinamento. Alimentando cordeiros mestiços Texel com dietas contendo $40 \%$ de concentrado, Pires et al. (2000) registraram 45,75 e 73,58 dias para que animais atingissem os pesos de abate de 28,0 e $33,0 \mathrm{~kg}$, respectivamente. Além do efeito do plano nutricional sobre o tempo de terminação dos ovinos no confinamento, outros fatores, como o genótipo, também podem influenciar essa variável. Santra \& Karim (2001) observaram que ovinos Malpura, $3 / 4$ Awassi $\times$ Malpura e Awassi $\times$ (Awassi $\times$ Malpura) alimentados com dietas com $60 \%$ de concentrado permaneceram em torno de 79, 64 e 54 dias em confinamento, evidenciando que o aumento de genes da raça Awassi melhorou o desempenho dos animais.

Neste experimento, o consumo total de MS decresceu $(\mathrm{P}<0,05)$ de 111,50 para $56,74 \mathrm{~kg}$ (Tabela 3$)$ quando utilizadas dietas com 20 e $80 \%$ de concentrado, respectivamente, ou seja, parte da MS (aproximadamente $0,879 \mathrm{~kg}$ ) foi economizada por dia a cada unidade percentual de concentrado incluído na dieta. No entanto, os consumos de MS, expressos em kg/dia, em porcentagem (\%), em g/kg PV/dia e em gramas por unidade de peso metabólico ( $\mathrm{gMS} / \mathrm{PV}^{0,75}$ ), foram crescentes $(P<0,05)$ em relação aos níveis de concentrado. 
O consumo de MS foi de 0,925; 0,964; 1,003 e 1,124 kg/ dia para os ovinos alimentados com dietas contendo 20,40 , 60 e $80 \%$ de concentrado. Como demonstrado na Tabela 2 , os teores de FDN das dietas foram de 65,$41 ; 54,47 ; 462,8$ e $30,85 \%$ e os coeficientes de digestibilidade aparente da MS (Tabela 4) 62,47; 73,23; 73,35 e 80,22\% para os respectivos níveis de concentrado. Os maiores valores de consumo diário de MS (Figura 1) foram obtidos nos animais alimentados com dieta contendo aproximadamente $30,85 \%$ de FDN ( $80 \%$ de concentrado), portanto, mais digestível e provavelmente com maior taxa de passagem. No nível mais baixo de concentrado, o consumo reduziu conforme os níveis de FDN aumentaram. Valdés et al. (2000) verificaram que as taxas de passagem da digesta pelo rúmen $\left(\mathrm{k}_{1}\right)$ e pelo ceco e cólon proximal $\left(\mathrm{k}_{2}\right)$ de ovelhas não-gestantes e nãolactantes alimentadas com dietas contendo 20, 40, 60 e 80\% de concentrado decresceram linearmente, com valores de 0,$0515 ; 0,0528 ; 0,0467$ e $0,0317\left(\mathrm{k}_{1} /\right.$ hora $)$ para a taxa de passagem pelo rúmen e de 0,$1005 ; 0,0758 ; 0,0668$ e 0,0589 $\left(\mathrm{k}_{2} /\right.$ hora $)$ para a taxa de passagem pelo ceco e pelo cólon proximal, enquanto aquelas alimentadas com dietas com maiores proporções de concentrado aumentaram o tempo médio de retenção de partículas no intestino delgado.

Os valores de ingestão de MS obtidos neste estudo foram superiores aos descritos por Zeola (2002), que também verificou que a ingestão de MS em ovinos Morada Nova aumentou de acordo com o nível de concentrado da dieta e que o nível de $60 \%$ proporcionou maior ingestão $(0,720 \mathrm{~kg} /$ dia) em comparação aos níveis de $45 \%$ (0,614 kg/dia) e 30\% $(0,539 \mathrm{~kg} / \mathrm{dia})$. Esses resultados provavelmente estão relacionados a fatores como a qualidade do volumoso, a composição do concentrado e o peso vivo dos animais.

Para o consumo de MS por unidade de peso metabólico, foram encontrados valores de 81,55; 85,84; 89,69 e 99,88 g/dia nos quatro níveis de níveis de concentrado. O NRC (1985) sugere que o consumo de MS por unidade de peso metabólico (g MS/PV0,75) em animais com $20 \mathrm{~kg}$ de PV alimentados com dietas de 2,9 Mcal de EM/kg MS é de 105,7 g/ dia. Pelo AFRC (1993), esse consumo seria de 95,0 g/dia para a mesma faixa de peso vivo do animal eno mesmo plano nutricional.

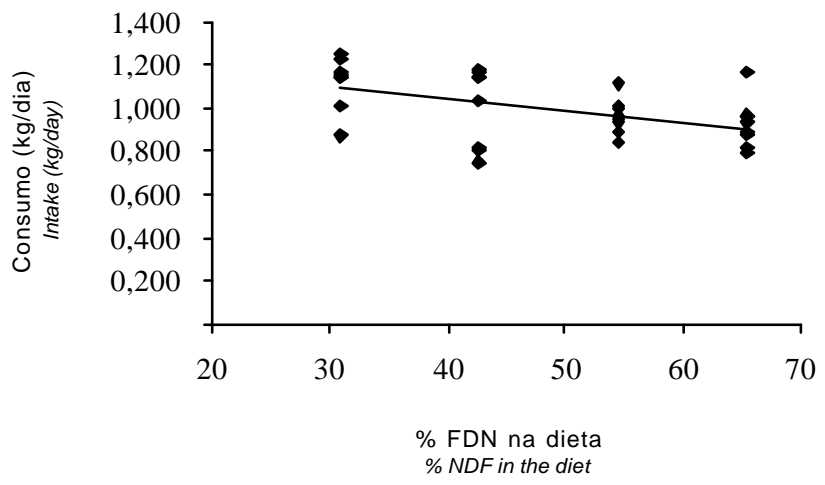

Figura 1 - Consumo de MS em ovinos alimentados com dietas com diferentes níveis de FDN.

Figure 1 - DM intake in function of NDF content in the diet.

Tabela 3 - Desempenho de ovinos Morada Nova alimentados com dietas com diferentes níveis de concentrado Table 3 - Performance of Morada Nova sheep fed diets with increasing concentrate levels

\begin{tabular}{|c|c|c|c|c|c|c|c|}
\hline & \multicolumn{4}{|c|}{$\begin{array}{l}\text { Nível de concentrado (\%) } \\
\text { Concentrate level }\end{array}$} & \multirow[t]{2}{*}{$\mathrm{CV}(\%)$} & \multirow[t]{2}{*}{$\begin{array}{l}\text { Equação de regressão } \\
\text { Regression equation }\end{array}$} & \multirow[t]{2}{*}{$r^{2}$} \\
\hline & 20 & 40 & 60 & 80 & & & \\
\hline $\mathrm{PV}$ inicial, $\mathrm{kg}$ (Initial $B W, \mathrm{~kg}$ ) & 20,37 & 19,42 & 19,0 & 19,92 & - & - & - \\
\hline PV abate, $\mathrm{kg}$ (Slaughter $B W, \mathrm{~kg}$ ) & 30,92 & 30,68 & 30,42 & 30,84 & 3,28 & $\hat{\mathrm{y}}=30,71^{\mathrm{ns}}$ & - \\
\hline Dias de confinamento (Feedlot days) & 123,37 & 86,62 & 75,25 & 52,50 & 34,58 & $\hat{y}=140,438-1,12 * C^{1}$ & 0,96 \\
\hline Consumo MS total, $\mathrm{kg}$ (Total DM intake, $\mathrm{kg}$ ) & 111,50 & 82,22 & 70,62 & 56,74 & 25,83 & $\hat{y}=124,245-0,879408 * C$ & 0,95 \\
\hline Consumo MS, $\mathrm{kg} / \mathrm{dia}$ (DM intake, $\mathrm{kg} / \mathrm{dia}$ ) & 0,925 & 0,964 & 1,003 & 1,124 & 13,14 & $\hat{\mathrm{y}}=0,84478+0,00319125 * \mathrm{C}$ & 0,91 \\
\hline Consumo MS, \% (DM intake, \%) & 3,63 & 3,83 & 4,01 & 4,45 & 9,74 & $\hat{\mathrm{y}}=3,32047+0,0132902 * \mathrm{C}$ & 0,95 \\
\hline $\mathrm{g} \mathrm{MS} / \mathrm{kg}$ peso vivo/dia ( $g$ DM/kg BW/day) & 36,32 & 38,35 & 40,13 & 44,58 & 9,74 & $\hat{y}=33,2047+0,132902 * C$ & 0,95 \\
\hline g MS/kg PV $0,75 / \mathrm{dia}\left(\mathrm{g} D M / B W^{0,75 / d a y)}\right.$ & 81,55 & 85,84 & 89,69 & 99,88 & 10,18 & $\hat{y}=74,5332+0,294191 * C$ & 0,94 \\
\hline Ganho de peso total, $\mathrm{kg}$ (Total weight gain, $\mathrm{kg}$ ) & 10,54 & 11,25 & 11,42 & 10,91 & 9,66 & $\hat{\mathrm{y}}=11,0^{\mathrm{ns}}$ & - \\
\hline Ganho de peso diário, $\mathrm{kg}$ (Daily weight gain, $\mathrm{kg}$ ) & 0,089 & 0,134 & 0,168 & 0,224 & 28,59 & $\hat{\mathrm{y}}=0,044331+0,0021982 * \mathrm{C}$ & \\
\hline $\mathrm{CA}(\mathrm{kg} \mathrm{MS} / \mathrm{kg}$ GPD) $(F C \mathrm{~kg} D M / D W G)$ & 10,51 & 7,32 & 6,03 & 5,09 & 22,59 & $\hat{\mathrm{y}}=11,9866-0,090517 * \mathrm{C}$ & 0,92 \\
\hline Eficiência alimentar, \% (Feed efficiency, \%) & 9,86 & 14,46 & 17,16 & 20,35 & 22,59 & $\hat{y}=6,91733+0,170812 * C$ & 0,99 \\
\hline
\end{tabular}

${ }^{1}$ Nível de concentrado (Concentrate level).

* Significativo a 1 e $5 \%$ de probabilidade pelo teste $\mathrm{t}$ (Significant at 1 and $5 \%$ levels at probability by $t$ test).

ns - não-significativo (ns - not significant). 
Barros et al. (1994) relataram valores médios de 77,3; 79,$2 ; 82,8$ e 70,3 g MS/PV0,75 para ovinos alimentados com dietas com 15, 30, 45 e $60 \%$ de concentrado, com efeito quadrático para o genótipo Somalis $\times$ SRD, enquanto o consumo de MS nos ovinos Santa Inês $\times$ SRD (média de 74,63 gMS/kg PV0,75) não foi influenciado pela relação volumoso:concentrado.

Observou-se também efeito linear $(\mathrm{P}<0,05)$ do plano nutricional sobre o ganho de peso diário, com valores de 0,$089 ; 0,134 ; 0,168$ e $0,224 \mathrm{~kg} /$ dia para os animais alimentados com 20, 40, 60 e $80 \%$ de concentrado (Tabela 3 ). Evidenciou-se que o aporte de energia na dieta e seu consumo elevaram o ganho de peso dos animais (Figura 2). Considerando os efeitos lineares do ganho de peso diário e do

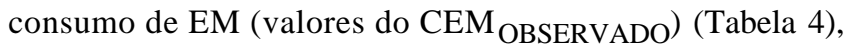
pode-se inferir que, a cada unidade percentual de concentrado na dieta, houve aumento de aproximadamente 0,016 Mcal na ingestão de energia e, conseqüentemente, acréscimo de 2,198 g no peso corporal dos animais.

Mahgoub et al. (2000) verificaram que ovinos Omani alimentados com dietas contendo 2,39; 2,47 e 2,72 Mcal de $\mathrm{EM} / \mathrm{kg} \mathrm{MS}$ apresentaram ganhos de peso de 90, $115 \mathrm{e}$ $147 \mathrm{~g} /$ dia e atribuíram a maior taxa de ganho ao aumento da ingestão de MS e de EM da dieta com maior nível deenergia. Sheridan et al. (2003) relataram ganhos de 0,203 e 0,281 kg para ovinos Merino alimentados com dietas de 2,36 e 2,89 Mcal de EM/kg MS. Em experimento com dietas conten do 40 e $85 \%$ de concentrado, Haddad \& Husein (2004) observaram que os ganhos diários de ovinos Awassi foram de 178,0 e 258,0 g, respectivamente.

A conversão alimentar melhorou linearmente $(\mathrm{P}<0,05)$ com o nível de concentrado na dieta e atingiu valores de 10,51; 7,32; 6,08 e 5,09 kg MS/kg GPD. Esses resultados podem ser atribuídos ao percentual de eficiência alimentar,

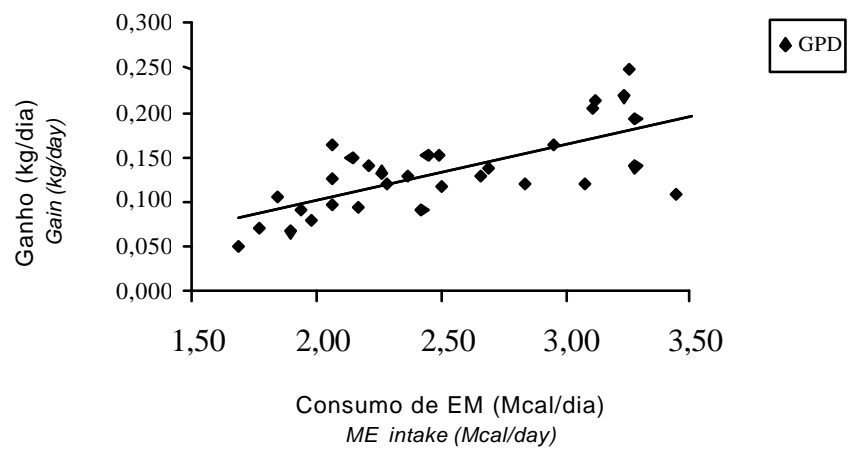

Figura 2 - Ganho de peso diário (GPD) em função do consumo de energia metabolizável (Mcal/dia).

Figure 2 - Daily weight gain ( $\mathrm{kg} / \mathrm{dia})$ in function of metabolizable energy intake (Mcal/day). que também teve comportamento crescente em relação aos níveis estudados. Os maiores percentuais $(17,16$ e 20,35\%) foram obtidos nas proporções de 60 e $80 \%$ de concentrado na dieta, respectivamente.

Ressalta-se que ovinos da raça Morada Nova normalmente são mantidos em ambiente semi-árido, em pastagens de caatinga nativa, e apresentam baixos índices produtivos, principalmente quando há escassez de alimentos nas épocas secas. Em caatinga raleada, com diferentes taxas de lotação, esses animais podem alcançar ganhos de 75 a 100 g/dia (Araújo Filho et al., 2002). Por outro lado, sob as condições intensivas deste experimento, esse mesmo genótipo atingiu ganhos próximos ao de algumas raças mais especializadas quando o plano nutricional foi melhorado, evidenciando seu potencial para ganho de peso. Portanto, essa raça deveria receber maior atenção em termos de conservação e melhoramento genético para essa característica.

Verificou-se efeito linear crescente $(\mathrm{P}<0,05)$ dos níveis de concentrado sobre os consumos de MO, PB, EE e NDT estimado e observado (NDT observado $_{\text {e NDT }}$ estimado), energia metabolizável estimada e observada $\left(\mathrm{CEM}_{\text {estimada }} \mathrm{e}\right.$ $\left.\mathrm{CEM}_{\text {observada }}\right), \mathrm{CT}$ e CNF e efeito linear decrescente $(\mathrm{P}<0,05)$ sobre os consumos de FDN e FDA (Tabela 4).

Como demonstrado na Tabela 5 , observou-se efeito linear crescente $(\mathrm{P}<0,05)$ dos níveis de concentrado sobre a digestibilidade de MS, MO e CT. Os coeficientes de digestibilidade de EE e CNF apresentaram comportamento quadrático $(\mathrm{P}<0,05)$, enquanto os coeficientes de digestibilidade de PB, FDN e FDA não foram influenciados pelos níveis de concentrado.

O consumo de MO apresentou valores de 0,841;0,892; 0,938 e $1,056 \mathrm{~kg} / \mathrm{dia}$. Os coeficientes de digestibilidade de MO foram de 63,68; 74,05; 74,29 e 81,19\% para as diferentes proporções de concentrado utilizadas neste experimento. A partir desses valores, os ovinos consumiram em torno de 0,535; 0,660; 0,697 e 0,857 kg de MO digestível, ou 20,96; 26,25; 28,01 e 33,99 g/kg PVmédio, de acordo com os níveis de concentrado.

Altas correlações entre a digestibilidade da MO e o teor energético dos alimentos ou das dietas foram relatadas pelo AFRC (1993) e Rocha Jr. et al. (2003). Pela estimativa de consumo de EM (AFRC, 1993), o resultado entre o consumo de MO digestível observado pelo fator 0,0157 seria 2,0; 2,48; 2,61 e 3,21 Mcal de EM, valores muito próximos aos do consumo de EM (Tabela 4).

Para o consumo de PB, obtiveram-se valores de 0,164 ; 0,180; 0,186 e 0,208 kg/dia, atribuídos ao aumento do teor de PB nas dietas e ao aumento do consumo de MS/dia. Ressalta-seque o menor consumo PB $(0,164 \mathrm{~kg})$, obtido nos animais alimentados com dietas com $20 \%$ de concentrado, 
Tabela 4 - Consumo de nutrientes por ovinos Morada Nova alimentados com dietas com diferentes níveis de concentrado Table 4 - Nutrient intake in Morada Nova sheep fed increasing levels of concentrate in the diet

\begin{tabular}{|c|c|c|c|c|c|c|c|}
\hline \multirow[t]{2}{*}{$\begin{array}{l}\text { Consumo de nutriente } \\
\text { Nutrient intake }\end{array}$} & \multicolumn{4}{|c|}{$\begin{array}{c}\text { Nível de concentrado (\%) } \\
\text { Concentrate level }\end{array}$} & \multirow[t]{2}{*}{$\mathrm{CV}(\%)$} & \multirow[t]{2}{*}{$\begin{array}{l}\text { Equação de regressão } \\
\text { Regression equation }\end{array}$} & \multirow[t]{2}{*}{$r^{2}$} \\
\hline & 20 & 40 & 60 & 80 & & & \\
\hline $\mathrm{MO}, \mathrm{kg}(O M)$ & 0,841 & 0,892 & 0,938 & 1,056 & 13,12 & $\hat{\mathrm{y}}=0,759656+0,00344290 * \mathrm{C}^{1}$ & 0,94 \\
\hline $\mathrm{PB}, \mathrm{kg}(C P)$ & 0,164 & 0,180 & 0,186 & 0,208 & 12,48 & $\hat{\mathrm{y}}=0,1500532+0,00069197 * \mathrm{C}$ & 0,96 \\
\hline $\mathrm{EE}, \mathrm{kg}(E E)$ & 0,042 & 0,050 & 0,053 & 0,062 & 12,81 & $\hat{\mathrm{y}}=0,0367053+0,00030563 * \mathrm{C}$ & 0,98 \\
\hline $\mathrm{FDN}, \mathrm{kg}(N D F)$ & 0,584 & 0,478 & 0,397 & 0,353 & 14,06 & $\hat{\mathrm{y}}=0,647464-0,00388075 * \mathrm{C}$ & 0,97 \\
\hline FDA, $\mathrm{kg}(A D F)$ & 0,305 & 0,235 & 0,183 & 0,148 & 14,42 & $\hat{\mathrm{y}}=0,348536-0,00261457 * \mathrm{C}$ & 0,98 \\
\hline $\mathrm{NDT}_{\text {estimado }}, \mathrm{kg}\left(T D N_{\text {estimated }}\right)$ & 0,544 & 0,646 & 0,734 & 0,876 & 13,27 & $\hat{y}=0,429648+0,00541326 * C$ & 0,99 \\
\hline $\mathrm{NDT}_{\text {observado }}, \mathrm{kg}\left(T D N_{\text {observed }}\right)$ & 0,589 & 0,722 & 0,723 & 0,885 & 13,57 & $\hat{\mathrm{y}}=0,507945+0,00443943 * \mathrm{C}$ & 0,90 \\
\hline $\mathrm{EM}_{\mathrm{estimado}} \mathrm{Mcal} / \mathrm{dia}\left(M E_{\text {estimated }}\right.$, Mcal/day) & 1,976 & 2,334 & 2,656 & 3,172 & 13,26 & $\hat{\mathrm{y}}=1,55758+0,019454 * \mathrm{C}$ & 0,99 \\
\hline $\mathrm{EM}_{\text {observado }} \mathrm{Mcal} / \mathrm{dia}$ (MEobserved, Mcal/day) & 2,130 & 2,611 & 2,613 & 3,199 & 13,57 & $\hat{\mathrm{y}}=1,83641+0,0160502 * \mathrm{C}$ & 0,90 \\
\hline $\mathrm{CT}, \mathrm{kg}(T C)$ & 0,634 & 0,661 & 0,697 & 0,785 & 13,48 & $\hat{y}=0,572305+0,0024412 * C$ & 0,92 \\
\hline $\mathrm{CNF}, \mathrm{kg}(N F C)$ & 0,075 & 0,203 & 0,314 & 0,442 & 15,05 & $\hat{\mathrm{y}}=-0,044291+0,0060602 * \mathrm{C}$ & 0,98 \\
\hline
\end{tabular}

${ }^{1}$ Nível de concentrado (Concentrate level).

* Significativo a 1 e $5 \%$ de probabilidade pelo teste $\mathrm{t}$ (Significant at 1 and $5 \%$ levels of the probability by $t$ test).

ns - não-significativo(Not significant).

Tabela 5 - Coeficientes de digestibilidade aparente (\%) dos nutrientes em ovinos Morada Nova alimentados com dietas com diferentes níveis de concentrado

Table 5 - Apparent digestibility of nutrients in Morada Nova fed increasing levels of concentrate in the diet

\begin{tabular}{|c|c|c|c|c|c|c|c|}
\hline \multirow[t]{2}{*}{$\begin{array}{l}\text { Nutriente } \\
\text { Intake }\end{array}$} & \multicolumn{4}{|c|}{$\begin{array}{l}\text { Nível de concentrado (\%) } \\
\text { Concentrate level }\end{array}$} & \multirow[t]{2}{*}{$\mathrm{CV}(\%)$} & \multirow[t]{2}{*}{$\begin{array}{l}\text { Equação de regressão } \\
\text { Regression equation }\end{array}$} & \multirow[t]{2}{*}{$r^{2}$} \\
\hline & 20 & 40 & 60 & 80 & & & \\
\hline MS, $\%(D M)$ & 62,47 & 73,23 & 73,35 & 80,22 & 7,58 & $\hat{y}=58,9778+0,266889 * C^{1}$ & 0,88 \\
\hline $\mathrm{MO}, \%(O M)$ & 63,68 & 74,05 & 74,29 & 81,19 & 7,32 & $\hat{\mathrm{y}}=60,117+0,263812 * \mathrm{C}$ & 0,89 \\
\hline $\mathrm{PB}, \%(C P)$ & 79,27 & 82,32 & 79,65 & 81,04 & 5,99 & $\hat{y}=80,57^{\mathrm{ns}}$ & - \\
\hline $\mathrm{EE}, \%(O M)$ & 80,26 & 84,87 & 86,54 & 85,29 & 4,52 & $\hat{y}=72,7402+0,449638 C-0,00365874 * C^{2}$ & 0,65 \\
\hline FDN, \%(NDF) & 59,02 & 65,37 & 62,16 & 66,66 & 11,58 & $\hat{\mathrm{y}}=63,30^{\mathrm{ns}}$ & - \\
\hline FDA, \%(ADF) & 53,84 & 62,60 & 56,38 & 60,69 & 12,91 & $\hat{\mathrm{y}}=58,49^{\mathrm{ns}}$ & - \\
\hline $\mathrm{CT}, \%(T C)$ & 58,57 & 70,78 & 72,09 & 80,84 & 8,07 & $\hat{y}=53,5496+0,340503 * C$ & 0,92 \\
\hline $\mathrm{CNF}, \%(N F C)$ & 62,32 & 79,60 & 88,86 & 90,07 & 13,76 & $\hat{y}=37,0142+1,46653 C-0,0100413 * C^{2}$ & 0,91 \\
\hline
\end{tabular}

${ }^{1}$ Nível de concentrado (Concentrate level).

* Significativo a 1 e $5 \%$ de probabilidade pelo teste $\mathrm{t}$ (Significant at 1 and $5 \%$ levels at probability by $t$ test).

ns - não-significativo ( $n s-$ not significant).

representa 98,21\% do exigido pelo NRC (1985). A dieta desses animais tinha apenas feno de capim-tifton moído $(8,45 \%$ de PB) e farelo de soja (52,21\% de PB) como fontes de proteína, denotando que houve seleção de alimentos na quantidade total oferecida/dia, apesar de essa dieta ter sido fornecida na forma de mistura completa. Em termos gerais, a digestibilidade da PB foi alta $(80,57 \%)$ e superou a obtida por Alves et al. (2003b) em pesquisa com ovinos Santa Inês.

Foram registrados valores de 0,$042 ; 0,050 ; 0,053$ e $0,062 \mathrm{~kg}$ para o consumo de EE e de 80,$26 ; 84,87 ; 86,54$ e $85,29 \%$ para os coeficientes de digestibilidade desse nu- triente nos quatro níveis de concentrado utilizados. O aumento na ingestão desse nutriente também está relacionado ao consumo de MS e à disponibilidade de EE nas dietas, em torno de 4,14; 4,57; 4,96 e 5,36\% na MS (Tabela 2), que tiveram como principal fonte o óleo de soja degomado, utilizado para elevar os níveis de energia das dietas. Por outro lado, a digestibilidade do EE apresentou comportamento curvilíneo, com o ponto de máxima no nível de $61,45 \%$ de concentrado, no qual o coeficiente de digestibiliade do EE foi de 86,55\%. O NRC (2001) reporta que o EE não representa uma fração nutricionalmente uniforme e, 
portanto, não tem digestibilidade constante entre os alimentos, ao contrário dos ácidos graxos, o que evidencia valores de digestilidade de 95 a 100\%. Esse comitê utiliza a equação proposta por Allen (2000) para estimar o teor de ácidos graxos (ácidos graxos $=\% \mathrm{EE}$ na $\mathrm{MS}-1$ ).

Os consumo s de FDN $(0,584,0,478,0,397$ e $0,353 \mathrm{~kg} /$ dia) e FDA $(0,305,0,235,0,183$ e $0,148 \mathrm{~kg} /$ dia $)$ descresceram quando a relação volumoso:concentrado diminuiu. Os coeficientes médios de digestibilidade da FDN e FDA foram de 63,30 e 58,49\%, respectivamente, e as ingestões médias calculadas de FDN/kg de PV/dia foram de 22,88; 19,$01 ; 15,95$ e 14,00 g/dia, respectivamente, para as dietas com 20, 40, 60 e $80 \%$ de concentrado. Valdés et al. (2000), citados por Mertens (1987), comentaram que a repleção ruminal pode ocorrer quando a ingestão de FDN é de 10 a $12 \mathrm{~g} / \mathrm{kg} \mathrm{PV} /$ dia. Esses autores verificaram consumos de 12,$2 ; 12,4 ; 10,3$ e $6,5 \mathrm{~g} / \mathrm{kg}$ PV/dia para os níveis de 20, 40, 60 e $80 \%$ de concentrado e atribuíram esses valores ao baixo teor de FDN da alfafa.

Neste experimento, os valores de ingestão da FDN $/ \mathrm{kg}$ $\mathrm{PV} /$ dia foram superiores aos obtidos por Valdés et al. (2000), em decorrência do volumoso utilizado (feno de capim-tifton com 79,02\% de FDN na MS). Considerando os valores de ingestão de FDN/kg de PV observados, presume-se que a repleção ruminal por efeito do nível de FDN ocorreu quando os animais consumiram em torno de $22,88 \mathrm{~g} / \mathrm{kg}$ $\mathrm{PV} / \mathrm{dia}$, correspondente a $190 \%$ dos $12 \mathrm{~g}$ propostos por Mertens (1987), o que confirma a capacidade de melhor utilização da fibra dos alimentos volumosos pelos ovinos nativos Morada Nova.

É indiscutível a importância da fibra da forragem para o suprimento de carboidratos usados como fonte de energia pelos microrganismos do rúmen para produção de ácidos graxos voláteis (AGV) e estímulo da mastigação e ruminação, que contribuem para aumento da salivação e do tamponamento do pH ruminal (Van Soest, 1994; Cardoso et al., 2006). Os tempos de ruminação e mastigação observados por Fimbres et al. (2002a) variaram de 143 a 413 e de 235 a 588 minutos/dia em ovinos alimentados com dietas com 0 a $30 \%$ de volumoso, respectivamente.

Há relatos de que o aumento na ingestão de concentrado altera o ambiente ruminal e reduz a população de bactérias fibrolíticas diminuindo a digestibilidade dos componentes fibrosos da dieta, o que corresponde ao efeito associativo (Varga \& Kolver, 1997). Neste estudo, a digestibilidade aparente da FDN não sofreu influência $(\mathrm{P}>0,05)$ do nível de concentrado na dieta e apresentou média de 63,3\%. Os consumos de nutrientes energéticos (NDT e EM estimados e observados) foram muito próximos (Tabela 4) e indicam que a metodologia utilizada por meio do sistema de equa- ções propostas por Weiss (1999), também utilizada pelo NRC (2001), foi eficiente para estimar o valor energético das dietas experimentais e possibilitou obter coeficiente de determinação $\left(\mathrm{r}^{2}\right)$ de 0,99 para NDT e EM estimados.

Os consumos de NDT e EM aumentaram conforme a ingestão diária de MS e o nível de concentrado nas dietas experimentais (Tabela 4). Portanto, os valores discutidos a seguir referem-se apenas aos consumos de NDT e EM obtidos no ensaio de digestibilidade.

Os valores obtidos para o consumo de NDT foram de 0,$589 ; 0,722 ; 0,723$ e $0,885 \mathrm{~kg} / \mathrm{dia}$, enquanto, para a $\mathrm{EM}$, obtiveram-se 2,130; 2,611; 2,613 e 3,199 Mcal/dia. Esses valores evidenciaram que a inclusão de concentrado na dieta elevou em 4,44 g o consumo de NDT e em 0,016 Mcal o de EM/kg MS.

Considerando-se que ovinos da raça Morada Nova são animais de porte hipométrico e não são selecionados para produção de carne, pode-se afirmar que os consumos de MS, NDT e EM (Mcal/kg MS/dia) das dietas com maiores porcentagens de concentrado (a partir de 60\%) foram suficientes para atender aos requerimentos energéticos de mantença e ganho desses animais, ressaltando-se que esses valores foram próximos aos sugeridos pelo NRC (1985) e pela AFRC (1993). Gonzaga Neto et al. (2005) reportaram que as exigências energéticas de mantença e de ganho foram de 0,740 e 2,016 Mcal de EM para ovinos Morada Nova com $20 \mathrm{~kg}$ de PV ganhando $200 \mathrm{~g} / \mathrm{dia}$.

Em experimento com dietas com 40 e $85 \%$ de concentrado, Haddad \& Husein (2004) verificaram que ovinos Awassi consumiram 2,2 e 2,8 Mcal EM/kg MS/dia, respectivamente. Santra \& Karim (2001) notaram que ovinos Malpura e mestiços consumiram 2,4 Mcal EM/dia quando alimentados com dietas com $60 \%$ de concentrado.

$\mathrm{O}$ consumo de CT aumentou $(\mathrm{P}<0,05)$ e apresentou valores de 0,$634 ; 0,661 ; 0,697$ e $0,785 \mathrm{~kg}$, comportamento similar ao observado para o consumo de $\operatorname{CNF}(0,075 ; 0,203$; 0,314 e $0,442 \mathrm{~kg} / \mathrm{dia}$ ), quando as proporções de concentrado na dieta aumentaram. Os níveis de concentrado na dieta tiveram efeito crescente $(\mathrm{P}<0,05)$ sobre a digestibilidade aparente dos carboidratos totais $(58,57 ; 70,78 ; 72,09$ e $80,84 \%$ ), enquanto, para os CNF, o efeito foi quadrático $(62,32 ; 79,60 ; 88,86$ e 90,07\%) e adigestibilidade alcançou o valor máximo de $90,56 \%$ no nível de $73,15 \%$ de concentrado (Figura 3).

As dietas tinham em média 8,45; 19,08; 29,29 e 39,65\% de CNF na MS (Tabela 2), de acordo com os níveis de concen trado. No cálculo dos CNF foram incluídos todos os carboidratos solúveis em detergente neutro ou, efetivamente, facilmente fermentados pela microbiota ruminal. Pela classificação de Sniffen et al. (1992), esses carboidratos 
representam as frações $\mathrm{A}$ (composta de açúcares e ácidos orgânicos, de rápida degradabilidade) e $\mathrm{B}_{1}$ (amido, pectina e glucanos).

Valadares Filho et al. (2002) encontraram valores de 2,20; 66,25 e 7,40\% de amido no feno de tifton, no milho e no farelo de soja, respectivamente. Logo, estima-se que, do total de CNF ofertados aos animais, o amido foi o carboidrato mais consumido, uma vez que, nas dietas com 40,60 e $80 \%$ de concentrado, utilizou-se milho triturado como fonte energética. Ferreira (2005) comentou que o milho, quando usado em alta proporção em dietas mistas de volumoso e concentrado, pode provocar efeito negativo, reduzindo a digestibilidade da fibra. Presume-se, então, que os animais alimentados com $80 \%$ de concentrado consumiram em torno de $0,333 \mathrm{~kg}$ de amido, o queprovocou acidose ruminal em três animais desse tratamento,representando em torno de $37,5 \%$, com o aparecimento de sinais clínicos (inapetência, atonia ruminal, aumento da freqüência respiratória e diarréia) iguais aos observados por Brandini (1996) nos primeiros oito dias de confinamento. Esse resultado exigiu a administração oral de solução saturada de bicarbonato de sódio (50 g/100 mL de água/animal) durante três dias consecutivos e inclusão desse tamponante na formulação do concentrado. Patra et al. (1996) provocaram acidose em ovelhas por excesso de amido e verificaram que o $\mathrm{pH}$ do rúmen decresceu de 6,75 para 4,91 e 4,70 e que a concentração de ácido lático no líquido ruminal elevou de 0,312 para 17,73 e 26,268 mmol/ dL e a de ácido lático no sangue, de 1,29 para 4,26 e 4,87 $\mathrm{mmol} / \mathrm{dL}$ no tempo 0,12 e 24 horas após a alimentação, respectivamente.

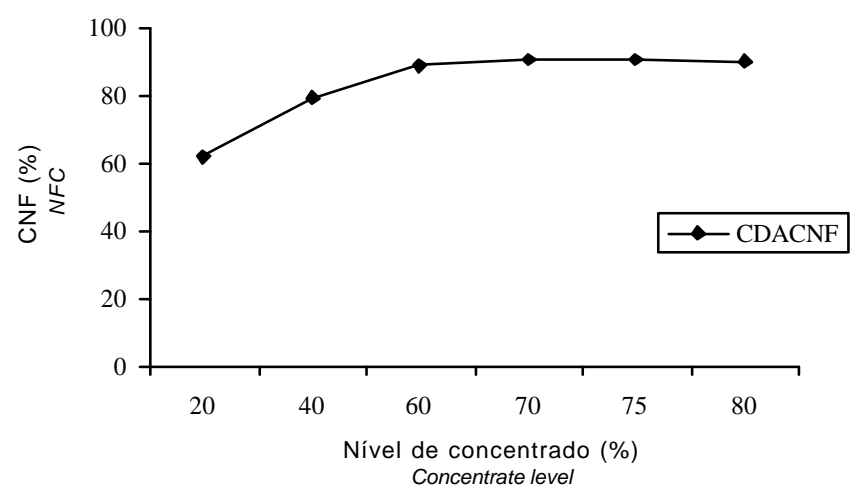

Figura 3 - Coeficiente de digestibilidade aparente dos carboidratos não-fibrosos (CNF).

Figure 3 - Apparent digestibility of nonfiber carbohydrates (NFC).

\section{Conclusões}

Ovinos Morada Nova em terminação alimentados com dietas formuladas com maiores níveis de concentrado apresentaram maior ganho de peso e melhor conversão alimentar e alcançaram mais rapidamente o peso para o abate.

Altos níveis de concentrado acarretam aumento na ingestão de MS e de nutrientes e diminuição do consumo de fibra.

Dietas contendo mais que $40 \%$ de concentrado melhoram a digestibilidade de MS e nutrientes, porém, em níveis superiores a 61,45 e 73,15\% de concentrado, as digestibilidades de EE e CNF diminuem.

A raça Morada Nova tem potencial para produção de carne em confinamento.

\section{Agradecimento}

Ao Conselho Nacional de Pesquisa e Desenvolvimento (CNPq), pela concessão da bolsa de Doutorado.

\section{Literatura Citada}

AGRICULTURAL AND FOOD RESEARCH COUNCIL - AFRC. Energy and protein requirements of ruminants. Wallingford: CAB International, 1993. 159p.

ALLEN, M.S. Effects of diet on short-term regulation of feed intake by lactating dairy cattle. Journal of Dairy Science, v.83, n.7, p.1598-1624, 2000.

ALVES, K.S.; CARVALHO, F.F.R.; VÉRAS, A.S.C. et al. Níveis de energia em dietas para ovinos Santa Inês: desempenho. Revista Brasileira de Zootecnia, v.32, n.6, p.1937-1944, 2003a (supl. 2).

ALVES, K.S.; CARVALHO, F.F.R.; VÉRAS, A.S.C. et al. Níveis de energia em dietas para ovinos Santa Inês: digestibilidade Apararente. Revista Brasileira de Zootecnia, v.32, n.6, 962 1968, 2003b (supl. 2).

ARAÚJO FILHO, J.A.; SOUZA NETO, M.; NEIVA, J.N.M. et al. Desempenho produtivo de ovinos da raça Morada Nova em caatinga raleada sob três taxas de lotação. Ciência Agronômica, v.33, n.1, p.51-57, 2002.

BARROS, N.N.; FIGUEIREDO, E.A.P.; FERNANDES, F.D. et al. Ganho de peso e conversão alimentar de cordeiros cruzas no Estado do Ceará. Pesquisa Agropecuária Brasileira, v.29, n. 8, p.1313-1317, 1994.

BARROS, N.N.; VASCONCELOS, V.R.; ARAÚJO, M.R.A. et al. Influência do grupo genético e da alimentação sobre o desempenho de cordeiros em confinamento. Pesquisa Agropecuária Brasileira, v.38, n.9, p.1111-1116, 2003.

BERCHIELLI, T.T.; ANDRANDE, P.; FURLAN, C.L. Avaliação de indicadores internos em ensaios de digestibilidade. Revista Brasileira de Zootecnia, v.29, n.3, p.830-833, 2000.

BRANDINI, J.C. Doenças em bovinos confinados. Campo Grande: EMBRAPA-CNPG, 1996. 62p. (Documentos, 65).

CARDOSO, A.R.; PIRES, C.C.; CARVALHO, C. et al. Consumo de nutrientes e desempenho de cordeiros alimentados com dietas que contêm diferentes níveis de fibra em detergente neutro. Ciência Rural, v.36, n.1, p.215-221, 2006. 
COELHO DA SILVA, J.F.; LEÃO, M.I. Fundamentos da nutrição dos ruminantes. Piracicaba: Livroceres, 1979. 380p.

FERREIRA, M.A. Palma forrageira na alimentação de bovinos leiteiros. Recife: Universidade Federal Rural do Pernambuco, 2005. 68p.

FIELD, R.A.; MAIORANO, G.; McCORNICK, R.J. et al. Effect of plane of nutrition and age on carcass maturity of sheep. Journal of Animal Science, v.68, p.1616-1623, 1990.

FIMBRES, H.; KAWAS, J.R.; HERNÁNDEZ-VIDAL, G. et al. Nutrient intake, digestibility, mastication and ruminal fermentation of lambs fed finishing ration with varios forage levels. Small Ruminant Research, v.43, p.275-281, 2002a.

FIMBRES, H.; HERNÁNDEZ-VIDAL, G.; PICÓN-RUBIO, J.F. et al. Productive performance and carcass characteristics of lambs fed finishing ration containing various forage levels. Small Ruminant Research, v.43, p.283-288, 2002b.

GRANT, R.J.; MERTENS, D.R. Influence of buffer $\mathrm{pH}$ and raw corn starch addition on in vitro fiber digestion kinetics. Journal of Dairy Science, v.75, p.2762-2768, 1992.

GONZAGA NETO, S.; SILVA SOBRINHO, A.G.; RESENDE, K.T. et al. Composição corporal e exigências Nutricionais de proteína e energia para cordeiros Morada Nova. Revista Brasileira de Zootecnia, v.34, n.6, p.2446-2456, 2005 (supl.).

HADDAD, S.G.; HUSEIN, M.Q. Effect of dietary energy density on growth performance and slaughtering characteristics of fattening Awassi lambs.Livestock Production Science, v.87, p.171-177, 2004.

HALL, M.B.; HOOVER, W.H.; JENNINGS, J.P. et al. A method for partitioning neutral detergent soluble carbohydrates. Journal Science Food Agriculture, v.79, p.2079-2086, 1999.

MAHGOUB, O.; LU, C.D.; EARLY, R.J. Effects of dietary energy density on feed intake, body weight gain and carcass chemical composition of Omani growing lambs. Small Ruminant Research, v.37, p.35-42, 2000.

MANSO, T.; MANTECÓN, A.R.; GIRALDEZ, F.J. et al. Anima performance and chemical body composition of lambs fed diets with different protein supplements. Small Ruminant Research, v.29, p.185-191, 1998

NATIONAL RESEARCH COUNCIL - NRC. Nutrient requeriments of sheep. 6.ed. Washington, D.C.: National Academy Press, 1985. 99p.

NATIONAL RESEARCH COUNCIL - NRC. Nutrient requirements of the dairy cattle. 7.ed. Washington: D.C. 2001. 363p.

NOTTER, D.R; KELLY, R.F.; McCLAUGHERTY, F.S. Effects of ewe breed and management system on efficiency of lamb production: II. Lamb growth, survival and carcass characteristics. Journal of Animal Science, v.69, p.22-23, 1991.

PATRA, R.C.; LAL, S.B.; SWARUP, D. Biochemical profile of rumen liquor, blood and urine in experimental acidosis in sheep. Small Ruminant Research, v.19, p.177-180, 1996.

PHY, T.S.; PROVENZA, F.D. Sheep fed grain prefer foods and solutions that attenuat acidosis. Journal of Animal Science, v.76, p.954-960, 1998 .

PIRES, C.C.; SILVA, L.F.; SCHLICK, F.E. et al. Cria e terminação de cordeiros confinados. Ciência Rural, v.30, n.5, p.875880,2000 .

QUINTERO, R.F.B.; MADRAZO, P.A.V.; AGUILAR, M.H Evaluación de razas terminales em esquemas de cruza comercial com ovejas de pelo F1. Técnica Pecuária México, v.40, n.1, p.71-79, 2002.

ROCHA JR., V.R.; VALADARES FILHO, S.C.; BORGES, A.M. et al. Determinação do valor energético de alimentos para ruminantes pelo sistema de equações. Revista Brasileira de Zootecnia, v.32, n.2, p.473-479, 2003

SANTRA, A.; KARIM, S.A. Nutrient utilization and growth performance of Malpura and Awassi x Malpura crossbred lambs under intensive feeding. Small Ruminant Research, v.41, p. $277-282,2001$
SANTRA, A.; CHATURVEDI, O.H.; TRIPATHI, M.K. et al. Effect of dietary sodium bicarbonate supplementation on fermentation characteristics and ciliate protozoal populations in rumen of lambs. Small Ruminant Research, v.47, p.203-212, 2003.

SHERIDAN, R.D.; FERREIRA, A.V.; HOFFMAN, L.C. Production efficiency of South African Mutton Merino lambs and Boer goat kids receiving either a low or a high energy feedlot diet Small Ruminant Research, v.50, p.75-82, 2003.

SILVA, D.J.; QUEIROZ, A.C. Análise de alimentos: métodos químicos e biológicos. 3.ed. Viçosa, MG: Universidade Federal de Viçosa, 2002. 235p.

SIQUEIRA, E.R. Sistemas de confinamento de ovinos para corte do sudeste do Brasil. In: SIMPÓSIO INTERNACIONAL DE CAPRINOS E OVINOS DE CORTE, 1., 2000, João Pessoa. Anais... João Pessoa: EMEPA-PB, 2000. p.107-117.

UNIVERSIDADE FEDERAL DE VIÇOSA - MG. Sistema de análises estatísticase genéticas - SAEG. Viçosa, MG: 2001. $301 \mathrm{p}$.

SNIFFEN, C.J.; ƠCONNOR, J.D.; Van SOEST, P.J. et al. A net carbohidrate and protein system for evaluating cattle diets: II. Carbohydrate and protein availability. Journal of Animal Science, v.70, p.3562-3577,1992.

SNOWDER, G.D.; GLIMP, H.A.; FIELD, R.A. Carcass characteristics and optimal slaughter weights in four breeds of sheep. Journal of Animal Science, v.72, p.932-937, 1994.

SUSIN, I. Confinamento de cordeiros. In: MATTOS, W.R.S. (Ed.) A produção animal na visão dos brasileiros. Piracicaba: Fundação de Estudos Agrários Luiz de Queiroz, 2001. p.454-459.

TITI, H.H.; TABBAA, M.J.; AMASHEH, M.G. et al. Comparative performance of Awassi lambs and Black goat kids on different crude proteína levels in Jordan. Small Ruminant Research, v.37, p.131-135, 2000.

VALADARES FILHO, S.C.; ROCHA JR., CAPELE, E.R. Tabelas brasileiras de composição de alimentos para bovinos. Viçosa, MG: Universidade Federal de Viçosa, 2002. 297p.

VALDÉS, C.; CARRO, M.D.; RANILLA, M.J. et al. Effect of forage to concentrate ratio in complete diets offered to sheep on voluntary food intake and some digestive parameters. Animal Science, v.70, p.119-126, 2000.

Van SOEST, P.J. Nutritional ecology of the ruminant. 2.ed. Ithaca: Cornell University Press, 1994. 476p.

Van SOEST, P.J.; ROBERTSON, J.B.; LEWIS, B.A. Methods for dietary fiber, neutral detergent fiber, and nonstarch polysaccharides in relation to animal nutrition. Journal of Dairy Science, v.74, p.3583-3597, 1991.

VARGA, G.A.; KOLVER, E.S. Microbial and animal limitations to fiber digestion and utilization. Journal Nutrition, v.127, p.819-823, 1997.

VASCONCELOS, V.R.; BARROS, N.N. Nutrição de caprinos e ovinos jovens. In: CONGRESSO NORDESTINO DE PRODUÇÃO ANIMAL, 2., 2000, Teresina. Anais... Teresina: Sociedade Nordestina de Produção Animal, 2000. p.143-153.

WEISS, W.P. Energy prediction equations for ruminant feeds. In: CORNELL NUTRITION CONFERENCE FEED MANUFACTURES, 61., 1999, Ithaca.Proceedings... Ithaca: Cornell University, 1999. p.176-185.

ZEOLA, N.M.B.L. Influência da alimentação nas características quantitativas da carcaça e qualitativas da carne de cordeiros morada nova. Jaboticabal: Universidade Estadual Paulista, 2002. 65p. Dissertação (Mestrado em Zootecnia) Universidade Estadual Paulista, 2002. 